\title{
Angiographic comparison of coronary artery disease between Asians and Caucasians
}

\author{
J. Dhawan and C.L. Bray
}

Department of Cardiology, Regional Cardiac Centre, Wythenshawe Hospital, Southmoor Road, Manchester M23 9LT, UK

\begin{abstract}
Summary: Asians in the United Kingdom surpass the already high mortality from coronary artery disease seen in Caucasians. In the present study, the angiographic features of consecutive series of 87 Caucasians, 83 British Asian and 30 Asian patients in India with coronary artery disease were assessed. Blood samples at fasting and after ingestion of $75 \mathrm{~g}$ of dextrose were taken to assess the extent of diabetes. Fasting blood samples were also taken for measurement of cholesterol, high-density lipoprotein cholesterol and triglyceride. Coronary angiograms were scored by two independent observers who were blinded to the patients' ethnic origin.

The Asians were younger than the Caucasians, but did not differ in their body mass index, systolic or diastolic blood pressure or in cigarette consumption. Lipids were similar apart from Indian Asians having lower cholesterol than British Asians, and Caucasians having lower triglyceride than Asians. There were more diabetics in Asians than in Caucasians. Asians in Britain wait longer than Caucasians and Asians in India from onset of angina to undergoing coronary angiography.

The presence of triple vessel disease was not significantly different $(P=0.19)$ in the three groups, that is, $38 \%, \mathbf{4 3} \%$ and $27 \%$ in Caucasians, British Asians and Indian Asians, respectively. The geometric mean coronary score was 26.3 (C.I. 22.6-30.6), 25.3(C.I. 21.8-29.4), and 25.2 (C.I. 19.6-32.5) in Caucasians, British Asians and Indian Asians, respectively. This difierence was not significant $(P=0.92)$. Total number of lesions more than three were similar, that is, in $25 \%$ Caucasian, $41 \%$ British Asian and $40 \%$ Indian Asian patients $(P<0.10)$. British Asians had less proximal disease $(P=0.0002)$, and Indian Asians less distal disease $(P=0.003)$ compared to Caucasians. Non-discrete (long) lesions were more prevalent in Asians than Caucasians $(P=0.0005)$.

The total number of lesions more than three in diabetic Asians was significantly more than in the non-diabetic, $71 \%$ versus $31 \%$ in British Asians $(P=0.002)$ and $90 \%$ versus $15 \%$ in Indian Asians $(P=0.0001)$. The relationship between diabetes and long lesions in both British and Indian Asians was highly significant $(P<0.00001$ and $P<0.001$, respectively).

Thus severity and extent of coronary disease is no difierent in Asians as compared to Caucasians. Diabetes is perhaps responsible for the more difiuse disease seen in Asians.
\end{abstract}

\section{Introduction}

South Asians (Asians) in the. United Kingdom (UK) have a higher mortality than Caucasians from coronary artery disease (CAD). ${ }^{1}$ Coronary angiography after first myocardial infarction (MI) in British Asians and Caucasians showed a higher incidence of triple vessel disease in the former. ${ }^{2}$ Significantly more severe disease has also been reported in British Asians than Caucasians. ${ }^{3}$ The distribution of disease, that is, proximal versus distal, however, has been found to be similar. ${ }^{3}$ There are no reports of angiographic comparisons

Correspondence: J. Dhawan, M.D., M.R.C.P., Ph.D., Scunthorpe General Hospital, Cliff Gardens, Scunthorpe, South Humberside, UK.

Accepted: 14 March 1994 of CAD between Asians from the UK, from the Indian sub-continent, and Caucasians.

The present study was undertaken, firstly to compare the coronary anatomy in Caucasian and Asian patients in the UK with CAD, and secondly to compare the coronary anatomy between Asian migrants to the UK and those who are still in their native country. By doing so a better understanding of the mechanisms responsible for the excess morbidity and mortality from CAD in Asians might be attained.

\section{Patients and methods}

Consecutive series of male Asian patients in the UK undergoing coronary angiography for inves- 
tigation of their chest pain between January 1988 and March 1990 were included in the study. There were 1,134 diagnostic coronary angiograms carried out in male Caucasian patients and 53 male Asian patients in the immediate preceding year of the study. Assuming that the same numbers would apply during the period of this study, every 23rd Caucasian male patient was included in the study. Only patients with more than $50 \%$ stenosis in one or more major epicardial coronary artery were included. Consecutive series of male Asian patients in Delhi, India, undergoing diagnostic coronary angiography between 1 January 1990 and 24 January 1990 with at least one or more vessels showing $50 \%$ stenosis were recruited in the study. Patients with familial hypercholesterolaemia were excluded.

Blood samples were taken within 3 months of angiography; in India samples were taken within a week of angiography. Blood was taken after an overnight fast and 120 minutes after an oral load of $75 \mathrm{~g}$ anhydrous dextrose, from all patients. Patients (both from UK and India) taking thiazide diuretics were asked to omit this medication 3 days prior to sampling and those taking beta blocker had their therapy substituted by a calcium antagonist in view of the influence of these drugs on serum lipid concentrations. ${ }^{4,5}$ This period of drug withdrawal prior to blood sampling, perhaps may not have been sufficient for this purpose, however, this was done so as not to upset the overall clinical condition of the patient. ${ }^{6}$

Serum glucose was measured by an automated glucose oxidase method in both the centres. Patients were classified as being diabetic if their blood glucose was above or equal to $11.1 \mathrm{mmol} / \mathrm{l}$ at 2 hour post glucose challenge. Cholesterol was estimated by a totally enzymatic method. ${ }^{7}$ HDL cholesterol was measured by the method based on the manganese phosphotungstate precipitation procedure. $^{8}$ Low-density lipoprotein (LDL) cholesterol was calculated by the formula: $\mathrm{LDL}=$ total cholesterol - HDL cholesterol $-0.46 \times$ triglyceride (all values in $\mathrm{mmol} / \mathrm{l}$ ). Triglyceride was determined after enzymatic hydrolysis with lipases. ${ }^{9}$

Severe angina was defined as angina at rest or on minimal exertion, all others were classified as mild to moderate. Five angiographic views were taken for each patient, these included left anterior oblique, right anterior oblique, left anterior oblique cranio caudal, right anterior oblique cranio caudal and antero posterior. Same views were taken from patients in India.

Coronary angiograms were scored by two independent experienced reporters in the UK (the authors). Each observer was blinded to the patient's name and ethnic origin. The scoring method adopted by the American Heart Association ${ }^{10}$ was used. Inter-observer variability was tested between the two reporters in the UK, this was extremely small. To assess intra-observer variability, 30 angiograms selected randomly were rescored by one observer (J.D.); this was also extremely small. Hence the angiograms in India were scored by only one observer (J.D.). All patients as per entry criteria had one or more vessel involvement and were classified as having single (SVD), double (DVD) or triple (TVD) vessel coronary disease, depending on the number of major epicardial vessels with at least one stenosis of greater than $50 \%$. Left main stem stenosis was taken as TVD.

In the right coronary artery (RCA), proximal was defined as the portion of the artery up to the origin of the posterior descending artery (PDA), if dominant, and the PDA and all other branches were defined as distal. In the left circumflex artery (CX), proximal was defined as up to the origin of first obtuse marginal (OM) and the remaining vessel with its branches as distal. The left anterior descending artery (LAD) was defined as proximal for the first two thirds of its course. All branches and the distal third of the LAD artery were defined as distal.

Non-discrete (long) lesions were defined as those occupying at least one third of the length of the segment (proximal or distal) of the artery. Extensive disease was defined as having a greater number of lesions and severe disease was one with higher coronary score, and diffuse disease was one with the presence of non-discrete lesions.

\section{Results}

There were 87 Caucasian, 83 British Asian and 30 Indian Asian patients meeting the entry criteria. Demographic details are shown in Table I. Asians were significantly younger than Caucasians, however, they did not differ in their body mass index (BMI), systolic or diastolic blood pressure, or their cigarette consumption.

British Asian patients after the onset of angina wait 18 months for coronary angiography as compared to 12 months in Caucasians $(P<0.001)$, and 12 months in Indian Asians $(P<0.001)$ (median duration). Prevalence of patients with mild to moderate and severe angina in British Asian and Caucasians were similar, however, more patients in Indian Asians had severe angina as opposed to mild to moderate angina (Figure 1).

Indian Asians had significantly lower cholesterol than British Asians but LDL cholesterol did not differ, while Caucasians had significantly lower triglyceride than Asians (Table I).

There were significantly more diabetics in Asians than in Caucasians, 21/83 (25\%) in British Asians, $10 / 30(33 \%)$ in Indian Asians and $7 / 87(8 \%)$ in Caucasians $\left(\chi^{2}(5)=30.6 ; P=0.00001\right)$. 
The inter-observer variability for coronary score between two observers was very small, that is, 0.9 with limits of agreement 4.2-6.0. The intraobserver variability was also very small, that is, -0.17 for coronary score with limits of agreement being -5.8 to 5.5 (all values in $\mathrm{mm}$ ).

In Caucasians 12/87 (14\%) had SVD, 42/87 (48\%) had DVD and 33/87 (38\%) had TVD, as compared to British Asian patients in whom 20/83 (24\%) had SVD, 29/83 (35\%) had DVD and 34/83 (41\%) had TVD. In Indian Asians 8/30 (27\%) had SVD, $14 / 30(47 \%)$ had DVD and $8 / 30(27 \%)$ had
TVD. There was no overall significant difference between the three groups $\left(\chi^{2}(4)=6.2 ; P=0.19\right)$ (Figure 2).

The geometric mean coronary score for Caucasian patients was $26.3(22.6-30.6)$ compared to $25.3(21.8-29.4)$ in British Asians; and 25.2 (19.6-32.5) in Indian Asians. There was no significant difference between the racial groups $(F$ $(2,197)=0.08 ; P=0.92)$. The total number of lesions by racial group are summarized in Table II. There was no significant difference noted.

The pattern of coronary artery disease differed in

Table I Demographic details of risk factors in the three patient groups

\begin{tabular}{|c|c|c|c|c|c|c|c|c|}
\hline & \multicolumn{2}{|c|}{$\begin{array}{c}\text { Caucasians } \\
\text { (C) }\end{array}$} & \multicolumn{2}{|c|}{$\begin{array}{c}\text { British Asians } \\
\text { (BA) }\end{array}$} & \multicolumn{2}{|c|}{$\begin{array}{c}\text { Indian Asians } \\
(I A)\end{array}$} & \multirow[t]{2}{*}{$C$ vs $B A$} & \multirow[t]{2}{*}{$B A$ vs $I A$} \\
\hline Number & & 87 & & 83 & & 30 & & \\
\hline Age (years) & 56.7 & $(8.7)$ & 51.9 & (7.1) & 50.0 & $(8.6)$ & $P<0.0001$ & NS \\
\hline BMI $\left(\mathrm{kg} / \mathrm{m}^{2}\right)$ & 25.7 & (3.2) & 25.5 & (9.9) & 23.9 & (2.9) & NS & NS \\
\hline Systolic BP (mmHg) & 137.8 & $(24.4)$ & 130.2 & (20.6) & 138.0 & $(19.5)$ & NS & NS \\
\hline Diastolic BP (mmHg) & 82.4 & $(7.8)$ & 79.1 & $(8.3)$ & 81.0 & $(7.2)$ & NS & NS \\
\hline $\begin{array}{l}\text { Mean lifetime cigarette } \\
\text { consumption in current } \\
\text { smokers }(1000 \text { s) }\end{array}$ & 196 & $(82-358)$ & 99 & $(22-231)$ & 142 & $(69-243)$ & NS & NS \\
\hline $\begin{array}{l}\text { Mean lifetime cigarette } \\
\text { consumption in } \\
\text { ex-smokers }(1000 \mathrm{~s})\end{array}$ & 218 & $(165-277)$ & 173 & $(130-221)$ & & $*$ & NS & - \\
\hline Total cholesterol (mmol/l) & 6.32 & $(1.14)$ & 6.16 & $(1.09)$ & 5.44 & $(1.06)$ & NS & $P<0.05$ \\
\hline LDL cholesterol $(\mathrm{mmol} / \mathrm{l})$ & 4.25 & $(1.09)$ & 3.90 & $(1.00)$ & 3.59 & $(0.82)$ & NS & NS \\
\hline $\begin{array}{l}\text { Log HDL cholesterol } \\
(\mathrm{mmol} / \mathrm{l})\end{array}$ & 1.08 & $(1.02-1.14)$ & 1.02 & $(0.97-1.07)$ & 0.89 & $(0.81-0.98)$ & NS & NS \\
\hline Log triglyceride $(\mathrm{mmol} / \mathrm{l})$ & 1.79 & $(1.60-2.01)$ & 2.39 & $(2.16-1.64)$ & 1.91 & $(1.68-2.19)$ & $P<0.001$ & NS \\
\hline
\end{tabular}

*No ex-smokers.

$\mathrm{NS}=$ not significant; $\mathrm{BMI}=$ body mass index; ranges or numbers in parentheses are $95 \%$ confidence intervals or standard deviations.

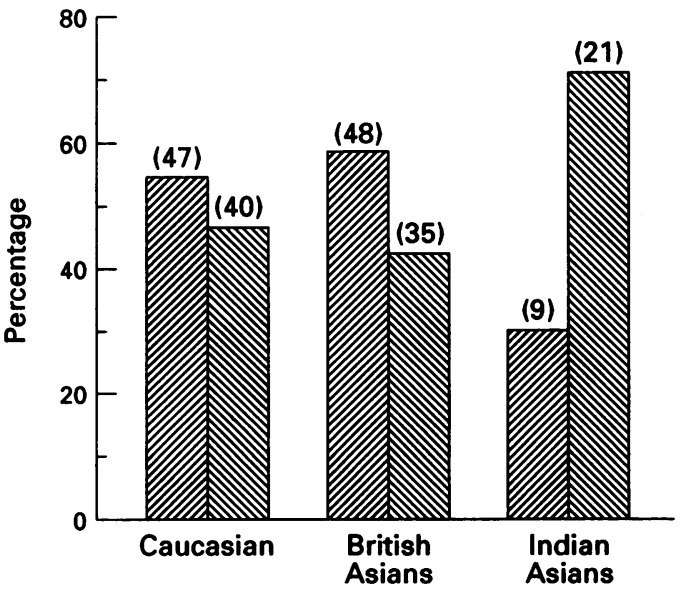

Figure 1 Prevalence of mild to moderate $(\mathbb{Z})$ and severe ( ) angina in the study groups $\left(\chi^{2}(2)=7.4\right.$; $P=0.02)$.

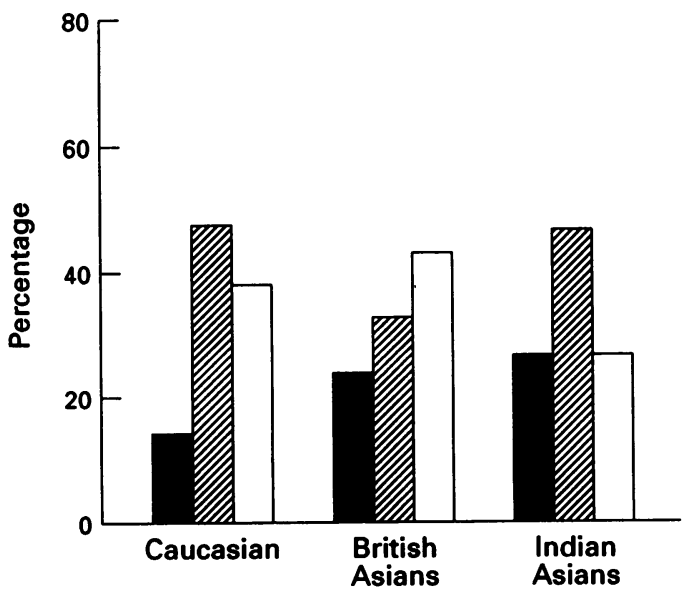

Figure 2 Prevalence of single ( $\square$ ), double ( $\mathbb{Z}$ ) and triple $(\square)$ vessel disease in the three groups $\left(\chi^{2}\right.$ (4) $=6.2 ; P=0.19$ ). 
the three groups (Table III). British Asians had less proximal disease as compared to the other groups $(P=0.0002)$. Indian Asians had less distal disease as compared to the other groups $(P=0.003)$. Non-discrete lesions were more prevalent in both the Asian groups as compared to Caucasians $(P=0.0005)$.

In Asians the total number of lesions were influenced by the diabetic state (Table IV), the total number of lesions more than three were significantly more in diabetics than in non-diabetics. The relationship between diabetes and presence of diffuse disease in both the Asian groups was highly significant (Table V).

\section{Discussion}

A similar proportion of British Asian and Caucasian patients were included in the study. The total number of Caucasian patients undergoing diagnostic coronary angiography in a year was far in excess of Asians, therefore Caucasian patients were chosen randomly throughout the period of the study. Angiograms were scored by two experienced independent observers who were unaware of the patients identity and ethnic origin, the difference between the two observers being negligible.

British Asians were significantly younger than

Table II Number of lesions in each racial group

\begin{tabular}{lrrr}
\hline Total number of lesions & Caucasians & British Asians & Indian Asians \\
\hline 1 & $14 / 87(16 \%)$ & $16 / 83(19 \%)$ & $8 / 30(27 \%)$ \\
2 & $32 / 87(37 \%)$ & $17 / 83(21 \%)$ & $7 / 30(23 \%)$ \\
3 & $19 / 87(22 \%)$ & $16 / 83(19 \%)$ & $3 / 30(10 \%)$ \\
$3+$ & $22 / 87(25 \%)$ & $34 / 83(41 \%)$ & $12 / 30(40 \%)$ \\
\hline$\chi^{2}(6)=10.72 ; P=0.09$. & &
\end{tabular}

Table III Pattern of coronary artery disease in the three groups

\begin{tabular}{lcccccc}
\hline Group & $\begin{array}{c}\text { Proximal } \\
\text { disease } \\
\text { present }\end{array}$ & $\begin{array}{c}\text { Proximal } \\
\text { disease } \\
\text { not present }\end{array}$ & $\begin{array}{c}\text { Distal } \\
\text { disease } \\
\text { present }\end{array}$ & $\begin{array}{c}\text { Distal } \\
\text { disease } \\
\text { not present }\end{array}$ & $\begin{array}{c}\text { Non-discrete } \\
\text { lesions } \\
\text { present }\end{array}$ & $\begin{array}{c}\text { Non-discrete } \\
\text { lesions } \\
\text { not present }\end{array}$ \\
\hline Caucasians & $68 / 87(78 \%)$ & $19 / 87(22 \%)$ & $63 / 87(72 \%)$ & $24 / 87(28 \%)$ & $13 / 87(15 \%)$ & $74 / 87(85 \%)$ \\
British Asians & $41 / 83(50 \%)$ & $42 / 83(50 \%)$ & $59 / 83(71 \%)$ & $24 / 83(29 \%)$ & $29 / 83(35 \%)$ & $54 / 83(65 \%)$ \\
Indian Asians & $23 / 30(77 \%)$ & $7 / 30(23 \%)$ & $12 / 30(40 \%)$ & $18 / 30(60 \%)$ & $11 / 30(37 \%)$ & $19 / 30(63 \%)$ \\
& $\chi^{2}(2)=17.4 ; P=0.0002$ & $\chi^{2}(2)=11.7 ; P=0.003$ & $\chi^{2}(2)=10.6 ; P=0.005$ \\
\hline
\end{tabular}

Table IV Relationship between diabetes and total number of lesions

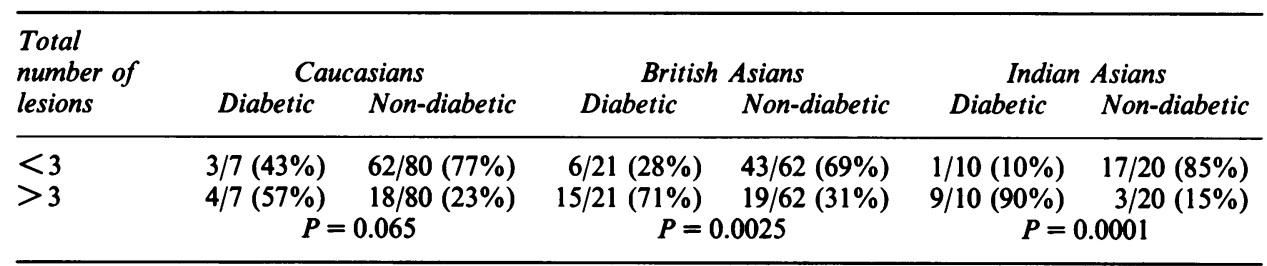

Table V Relationship between diabetes and non-discrete lesions

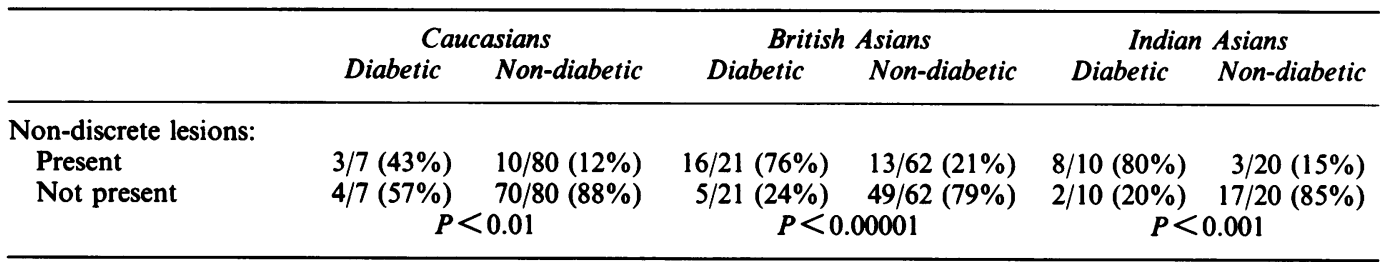


Caucasians, this could be due to selection perhaps from a relatively younger Asian population or coronary atherosclerosis occurring early in Asians. Hughes et al. ${ }^{2}$ seem to favour the second possibility in their study.

There was no significant difference between the number of vessels involved in the three groups studied. This is in contrast to the study by Hughes. ${ }^{2}$ He showed the proportion of Asian patients with three-vessel disease to be $53 \%$ as compared to $41 \%$ in the present study. This could be due to different entry criteria of patients in his study. Patients, after sustaining their first myocardial infarction, were studied by Hughes, ${ }^{2}$ while in the present study patients undergoing diagnostic angiography for their symptoms were recruited, therefore it is possible that, in the present study, patients were seen at an earlier stage in the spectrum of coronary atherosclerosis and hence the lower percentage of TVD noted. A higher prevalence of TVD was seen in Caucasians as compared to the previous study comparing Asians and Caucasians, ${ }^{2}$ this could reflect the regional differences between the prevalence of CAD in the UK. ${ }^{11}$

Interestingly the prevalence of TVD in Indian Asian patients was not as high as in the other groups. There are regional variations in the severity of CAD seen on coronary angiography from India. TVD has been reported from up to $54 \%$ from north of India ${ }^{12}$ and $37 \%$ from western part of India ${ }^{13}$ and $28 \%$ from south India. ${ }^{14}$ Meaningful comparison therefore, between Indian and British Asian patients is difficult.

There was no significant difference between the total coronary score in the three study groups. A previous study comparing Asians and Caucasians ${ }^{2}$ also showed similar results regarding total coronary score. The only other reported study comparing angiographic features of CAD in Asian and Caucasian patients from the $\mathrm{UK}^{3}{ }^{3}$ however, reported a higher coronary score in Asians as compared to Caucasians. The number of patients studied was only 34 in that study.

The total number of lesions in the three study groups was no different, suggesting that Asians do not have more extensive disease compared to Caucasians. The pattern of CAD differed in the three groups studied, Caucasians and Indian Asians had more proximal disease as compared to British Asians. Long, non-discrete lesions (diffuse disease) were seen more often in both the Asian groups as compared to Caucasians.

Asians and Caucasians did not differ much in their risk factor profile studied. They had similar BMI, blood pressure and cigarette consumption. In lipids, cholesterol was lower in Indian Asians but LDL cholesterol was no different. Triglyceride was, however, the only lipid fraction higher in Asians as compared to Caucasians.

Prevalence of diabetes was remarkably higher in Asians than in Caucasians. Diabetes was strongly associated with the type of angiographic CAD seen in Asians. CAD was more extensive in diabetics than non-diabetics in Asians, similarly diffuse disease was more prevalent in diabetic Asians than non-diabetics. Effect of diabetes on coronary atherosclerosis is complex. Krolewski et al. ${ }^{15}$ hypothesize that the diabetic state acts mainly by accelerating the progression of the early atherosclerotic lesions, which occur even in the absence of diabetes at a young age, in the general population $^{16,17}$ rather than having a causal effect.

Further corroboration of the hypothesis that diabetes may not cause, but only progress the pre-existing atherosclerotic lesions, comes from studies that have shown that CAD is a rare complication of diabetes in certain populations. Pima American Indians have the highest incidence of non-insulin-dependent diabetes in the world but have very low prevalence of CAD. ${ }^{18}$ Many Japanese and Chinese diabetic patients develop renal complications but not CAD. ${ }^{15}$

British Asian patients wait significantly longer after onset of angina and undergoing coronary angiography. The cause or causes of this delay were not investigated in this study, therefore to ascribe this as a factor responsible for the differences observed in the coronary artery disease would be speculative. Indian Asian patients wait the same time as Caucasian patients in the UK from onset of angina to undergoing coronary angiography. Though the facilities for coronary angiography in India are limited, a comparable interval seen may be due to more patients with severe symptoms in them as compared to the other groups, thus prompting perhaps early referral and investigation.

In conclusion, severity of CAD does not differ in the three groups. Asians from both UK and India have more diffuse disease. Diabetes is strongly associated with extensive and diffuse CAD in Asians. There is delay in Asians in the UK undergoing coronary angiography after onset of angina. The cause or causes of this delay needs further investigation.

\section{Acknowledgements}

We wish to acknowledge the help of Dr D.S. Gambhir, Associate Professor of Cardiology, G.B. Pant Hospital, New Delhi, India, for support of the Indian part of the study, and Mrs Julie Morris, senior statistician, Withington Hospital, for statistical analysis. 


\section{References}

1. Marmot, M.G., Adelstein, A.M. \& Bulusu, L. Immigrant Mortality in England and Wales, 1970-1978. OPCS Studies of Medical and Population subjects, No. 47. HMSO, London, 1984.

2. Hughes, L.O., Ravel, U. \& Raftery, E.B. First myocardial infarction in Asian and White men. Br Med J 1989, 298: $1345-1350$

3. Lowry, P.J., Mace, P.J.E., Glover, D.R. \& Littler, W.A. The pattern and severity of coronary artery disease in Asians and Whites living in Birmingham. Postgrad Med $J$ 1983, 59: 634-635.

4. Neusy, A.-J. \& Lowenstein, J. Effects of prazosin, atenalol and thiazide diuretics on plasma lipids in patients with essential hypertension. Am J Med 1984, 80 (Suppl 2A): 94-99.

5. Grimm, R.H., Leon, A.S., Hunninghake, D.B., Lenz, K., Hannan, P. \& Blackburn, H. Effects of thiazide diuretics on plasma lipids and lipoproteins in mildly hypertensive patients. Ann Intern Med 1981, 99: 7-11.

6. Hughes, L.O. First myocardial infarction and cardiovascular risk factors in Asians and whites living in North West London. D.M. thesis, University of London, 1989.

7. Siedel, J., Schlumberger, J., Klose, S., Ziegenhorn, J. \& Whalefield, A.W. Improved reagent for the enzymatic determination of serum cholesterol. J Clin Chem Clin Biochem 1981, 19: 838-839.

8. Burstein, M., Scholnick, H.R. \& Morein, R. Methods of HDL cholesterol estimation. J Lipid Res 1970, 11: 583

9. Jacobs, N.J. \& VanDemark, P.J. Method of triglyceride estimation. Arch Biol 1960, 88: 250-255.
10. American Heart Association Committee Report. A reporting system on patients evaluated for coronary artery disease. Circulation 1975, 51: 7.

11. OPCS for England and Wales (1983-1988). University of London, London, 1988 (for the Coronary Prevention Group).

12. Wasir, H.S., Bharani, A.K. \& Bhatia, M.L. Correlation of risk factors with coronary angiographic findings in patients $\bar{G}$ of ischaemic heart disease. J Assoc Phys India 1987, 36: 483-487.

13. Pahaljani, D.B., Chawle, M.H. \& Kapashi, K.A. Coronary ڤ artery disease pattern in the young. J Assoc Phys India 1989, 37: $312-314$

14. Gupta, S.R., Gupta, S.K., Reddy, K.N. et al. Coronary artery disease in young Indian subjects. Indian Heart $J$ 1987, 39: 384-387.

15. Krowleski, A.S., Warram, J.H., Valsania, P. et al. Evolving natural history of coronary artery disease in diabetes mellitus. Am J Med 1991, 90 (Suppl 2A): 56-61.

16. Krolewski, A.S., Kosinski, E.J., Warram, J.H. et al. Magnitude of determinants of coronary artery disease in juvenileonset insulin dependent diabetes mellitus. Am J Cardiol 1987, N 59: 750-755.

17. Stary, H.C. Evolution and progression of atherosclerosis lesions in coronary arteries of children and young adults. Arteriosclerosis 1989, 9 (Suppl 1): 19-32.

18. Nelson, R.G., Sievers, M.L., Knowler, W.C. et al. Low incidence of fatal coronary heart disease in Pima Indians $\mathcal{S}$ despite high prevalence of non-insulin dependent diabetes. Circulation 1990, 80: 987-995. 